\title{
Power System Loss Minimization Using Optimal Placement of UPFC Given by Bat Algorithm
}

\author{
Bairu Vijay Kumar \\ Asst.professor,EEED, KITSW,India.Email: bairuvijaykumar@gmail.com
}

\begin{abstract}
In this paper a heuristic method for minimizing active power loss of the power system using Unified Power Flow Controller is proposed. The novelty of the proposed method is to use the Bat algorithm to find optimal location of UPFC. Bat algorithm provides superior searching ability. Here, the bat algorithm optimizes location of UPFC when the generator outage occurs in the system. Generator outage affects the power flows, bus voltages, power loss, real and reactive power. By placing The UPFC at the optimal location, performance of the system is analyzed. The proposed method is implemented in the MATLAB/Simulink platform and tested on IEEE 30 bus standard bench mark system. The proposed method's performance is evaluated by comparison with different conditions. The comparison results proved the effectiveness of the proposed method and confirm its potential to minimize power loss.
\end{abstract}

Keywords: Bat algorithm, Power loss, UPFC.

\section{INTRODUCTION}

The quantity of electrical power transmitted safely by a transmission system is restricted [1]. Electrical power utilities through the world are working under pressured, in order to maximize total capacities due to the the environmental along with economic constraints to emerge a new generating plants and transmission lines [2] [3]. Power flow in the lines and transformers shouldn't be allowed to raise into a level in which a haphazard occurrence might lead to the actual system fall down as cascaded breakdowns [4] [5]. With regard to managing the power transmission system, Flexible Alternating Current Transmission System (FACTS) is often a better device that's utilized [6-7]. FACTS is regarded "an electric power automated dependent process along with other fixed device in which present management of a number of AC transmission system parameters to build up controllability in addition to magnify power transfer capability" [8]. The actual several types of FACTS devices available for this function contains Static Var Compensator (SVC), Thyristor controlled series Capacitor (TCSC), Static Synchronous series compensator (SSSC), Static Synchronous Compensator (STATCOM), Unified Power Flow Controller (UPFC) and Interlink Power Flow Controller (IPFC) [9]. UPFC is probably the best FACTS devices which can control both active and reactive power flow in transmission line. [10].

The optimum position of UPFC device permits to manage its power flows for an interconnected system, and thus to raise the system load ability [11]. Various kinds of optimization algorithms are used to solve this sort of issue, for example genetic algorithms, reproduced annealing, tabu search and etc. [12].

This paper proposes a heuristic method for minimizing power loss in the power system using UPFC. The novelty of the proposed method is to use the Bat algorithm to find optimal location UPFC under generator outage conditions. When the generator outage occurs, which in turn affects the power flow constraints like voltage, power loss, real and reactive power? For improving the system performance, UPFC is placed in the optimum location given by Bat algorithm. The objective of this paper is to reduce the power loss. The rest of the paper is organized as follows: Recent research works are discussed in section 2. Section 3 deals with UPFC structure, problem formulation and Heuristic algorithm. Section 4 gives the results and section 5 concludes the paper.

\section{RECENT RESEARCH WORK: A BRIEF REVIEW}

Number of similar performs are available in literary works, which dependent on improving the power transfer ability to electrical power process. Some of them are usually assessed here.

Mark Ndubuka Nwohu[13] presented an approach to find and choose the optimal location of Unified Power Flow Controller (UPFC) based on the sensitivity of the total system active power loss with respect to the control variables of the Unified Power Flow Controller (UPFC). The control system of the UPFC's injection model is developed and its contributions to avoiding a 


\section{International Journal of Research in Advent Technology, Vol.7, No.5, May 2019 E-ISSN: 2321-9637 Available online at www.ijrat.org}

voltage collapse are explored by analyzing a multimachine test system.

Seyed Abbas Taher et al. have got introduced this demands connected with hybrid immune algorithm to have the optimum location of UPFCs for attaining minimum total active and reactive power production cost of generators and reducing the installation cost of UPFCs [14].. They executed simulations upon IEEE 14bus and 30-bus test system.

Farangfar et al. [15] used, the UPFC injection model and investigated its effect on load flow and loss reduction in power systems. In this study, the NewtonRaphson algorithm is modified to consider the benefits of having a UPFC in the power system. Simulations have been implemented in MATLAB and the IEEE 14bus system has been used as a case study.

Chuan Wang et al. [16] have planned a new hybrid topology scale-free Gaussian-dynamic particle swarm (HTSFGDPS) optimization algorithm for real power loss minimization problem of power system. Many people focus on a new combination of swarm intelligence optimization theory and complex network theory, as well as its application to electric power system.
B.Vijay kumar et al have attempted the problem of optimal location of UPFC to minimize power loss of power system using Artificial Bee Colony algorithm [17]. They were carried out simulation studies on IEEE 30 bus system.

\section{POWER SYSTEM MODEL WITH UPFC}

The UPFC (unified power flow controller) is a FACTS device able to control simultaneously active power flows, reactive power flows and voltage magnitude at the UPFC terminals. UPFC consist of two voltage source converters, i.e., converter 1 and converter 2 , connected back to back through a common DC link provided by a DC storage capacitor. The converter 1 is a shunt connected voltage source converter, which is used to generate or absorb controllable reactive power and shunt reactive compensation for the line [18]. The converter 2 performs the main function of UPFC by bringing in an $\mathrm{AC}$ voltage with magnitude that can be controlled and the phase angle is in series with the transmission line through a series transformer. The necessary reactive power is supplied or absorbed locally by converter 2 and active power is replaced as a consequence of the series injection voltage $[18,19]$. The UPFC structure basic arrangement between $i$ and $j$ bus is described in the following figure 1 .

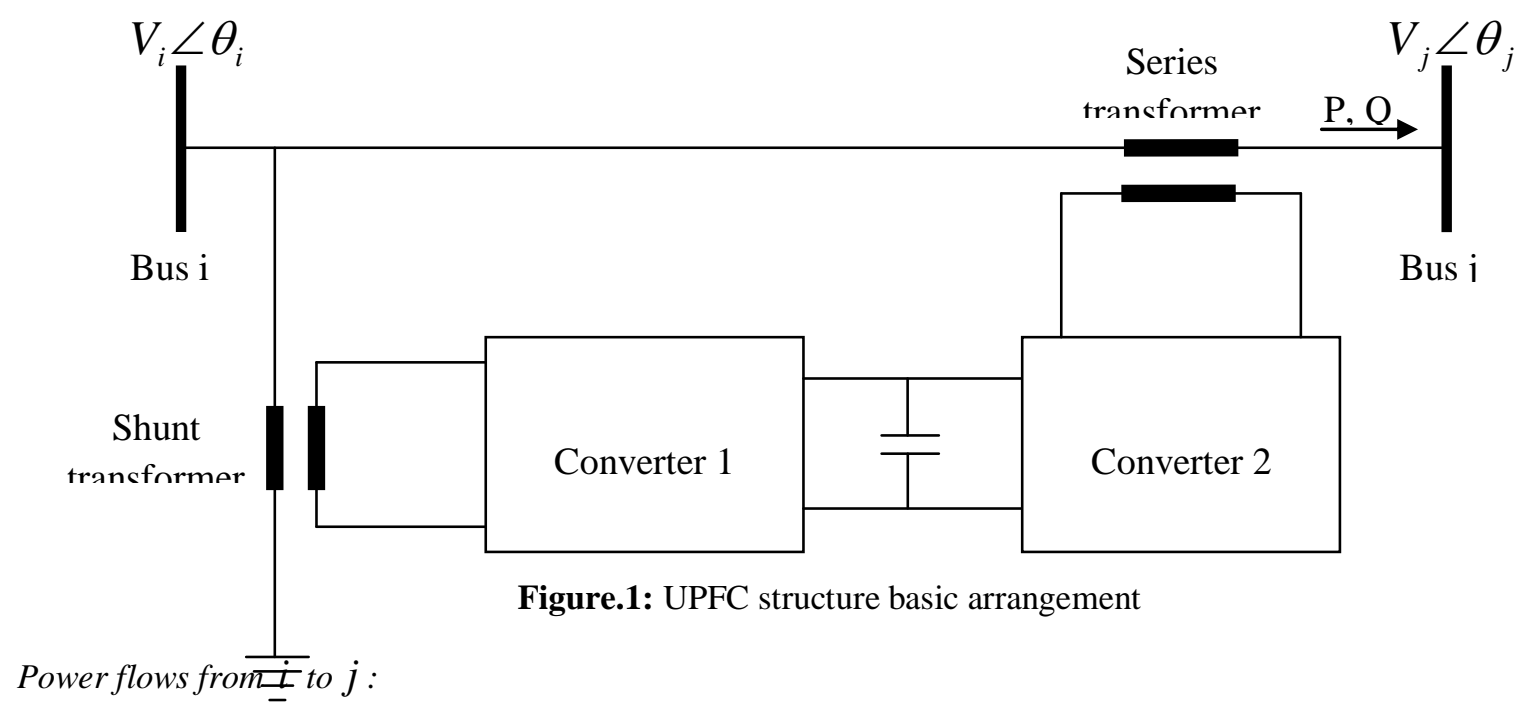




$$
\begin{aligned}
P_{i j}(t)= & \left(V_{i}{ }^{2(t)}+V_{k l}{ }^{2(t)}\right) G_{i j}{ }^{(t)}+2 V_{i}{ }^{(t)} V_{k l}{ }^{(t)} G_{i j}{ }^{(t)} \cos \left(\alpha_{k l}-\phi_{j}\right) \\
& -V_{j}{ }^{(t)} V_{k l}{ }^{(t)}\left[G_{i j}{ }^{(t)} \cos \left(\alpha_{k l}-\phi_{j}\right)+b_{i j}{ }^{(t)}\left(\sin \alpha_{k l}-\phi_{j}\right)\right] \\
& -V_{i}^{(t)} V_{j}{ }^{(t)}\left(G_{i j}{ }^{(t)} \cos \phi_{i j}+b_{i j}{ }^{(t)} \sin \phi_{i j}\right) \\
Q_{i j}(t)= & -V_{i}^{(t)} I^{(t)}-V_{i}{ }^{2(t)}\left(b_{i j}{ }^{(t)}+B / 2\right) \\
& -V_{i}^{(t)} V_{k l}{ }^{(t)}\left[G_{i j}{ }^{(t)} \sin \left(\alpha_{k l}-\phi_{i}\right)+b_{i j}{ }^{(t)}\left(\cos \alpha_{k l}-\phi_{i}\right)\right] \\
& -V_{i}{ }^{(t)} V_{j}{ }^{(t)}\left(G_{i j}{ }^{(t)} \sin \phi_{i j}-b_{i j}{ }^{(t)} \cos \phi_{i j}\right)
\end{aligned}
$$

Where, $G_{i j}+j b_{i j}=\frac{1}{R_{i j}+j X_{i j}}, V_{i}$ and $V_{j}$ are the voltage of the buses $i$ and $j$ and $V_{k l}$ is the voltage of the compensating device,

The above equations power flow equations of UPFC. Initially the system is in stable condition and whenever the generator outage occurs, the power flows of the system are disturbed. This causes increase in power loss. The increased power loss can be reduced by connecting UPFC at the optimum location, which is given by Bat algorithm. The required objective function and the constraints are described in the following section 3.1.

\subsection{Determination of optimal location of UPFC using Bat algorithm}

This section describes about the determination of the UPFC location using bat algorithm. The bat algorithm is the heuristic search optimization algorithm, which works based on the echolocation behavior of bats [20]. Here, the Newton Raphson (N-R) method is used for the load flow analysis of the IEEE standard bench mark system. Then the generator outage is introduced in the system, during this time the bat-inspired algorithm is used to find the optimum location. At the beginning, the input micro-bats like voltage at each bus and the power loss are initialized, which is given in the following equation (3).

$$
B_{i}=\left[\left(V_{1}, P_{L 1}\right)^{1},\left(V_{2}, P_{L 2}\right)^{2},\left(V_{3}, P_{L 3}\right)^{3} \ldots\left(V_{n}, P_{L n}\right)^{n}\right.
$$

Where, $B_{i}$ is the micro-bats. The input bus voltage is randomly generated with the required $n$ dimensions search space. Here, each micro-bat have the velocity vector $\left(v_{i}\right)$ and position vector $\left(x_{i}\right)$ and echolocation parameters like frequency $\left(f_{i}\right)$, pulse rate $\left(r_{i}\right)$ and the loudness parameters $\left(l_{i}\right)$, which are given in the following equation (4), (5) and (6).

$$
f_{\min } \leq f_{i} \leq f_{\max }
$$

$$
r_{\min } \leq r_{i} \leq r_{\max }
$$

$$
l_{\min } \leq l_{i} \leq l_{\max }
$$

Here, we assign the frequency range $f_{\text {min }}=0$ and $f_{\max }=1$, the pulse rate minimum value is $r_{\min }=0.5$ and the loudness maximum value is $l_{\max }=1$. The remaining values are determined by the )$^{n}$ following equation (7).

$$
l_{\min }=\frac{1}{\sqrt{n_{\mathrm{sec}}}} \text { and } r_{\max }=1-\frac{1}{n_{d}} \leq 1
$$




\section{International Journal of Research in Advent Technology, Vol.7, No.5, May 2019 E-ISSN: 2321-9637 Available online at www.ijrat.org}

Where, $n_{\text {sec }}$ is the number of sections in the discrete set used for sizing the design variable and $n_{d}$ is the number of discrete design variables. Then the objective function is evaluated, using the following equation (8).

$$
P_{l o s s}=\sum_{k \in N_{E}} g_{k}\left(V_{i}^{2}+V_{j}^{2}-2 V_{i} V_{j} \cos \theta_{i j}\right)
$$

The current populations of micro-bats are randomly updated based on the frequency and the velocity. The frequency and the velocity calculation are explained in the following equation (9).

$$
f_{i}^{t}=f_{\min }+\left(f_{\max }-f_{\min }\right) u_{i}
$$

Where, $u_{i}$ is the random number of values, which is selected from 0 to 1 , then the frequency is applied into the velocity equation, which can be described in the following.

$v_{i}^{t}=\operatorname{round}\left[v_{i}^{t-1}+\left(X_{i}^{t-1}-X_{\Psi}\right) u_{i}\right]$

Where, $v_{i}^{t}$ and $v_{i}^{t-1}$ are the velocity vectors of the microbats at the time steps $t$ and $t-1, X_{i}^{t}$ and $X_{i}^{t-1}$ are the position vectors of the micro-bats at time steps $t$ and $t-1, X_{\Psi}$ is the current global best solution. Here after the local search is performed in the randomly selected population that is described in the following equation (11).

$x_{i}^{t}=x_{i}^{t-1}+\xi_{i, j} l_{a v g}^{t}$

Where, $\xi_{i, j}$ is a random number between -1 and 1 , $l_{\text {avg }}^{t}$ is the average value of loudness at time step $t$. Then find the fitness of the new micro-bats using equation (9) and improve the echolocation parameters.

$l_{i}^{\prime}=a . l_{i}$ and $r_{i}^{t+1}=r_{\max }[1-\exp (\gamma t)]$
Where, $l_{i}$ and $l_{i}$ are the previous and updated values of the loudness, $r^{t+1}$ is the pulse rate of the micro-bats in time step , $a$ and $\gamma$ are the adaptation parameters of the loudness and pulse rate. Then the steps to find the optimum location are described below.

\section{Steps to find the optimum location}

Step 1: Initialize the micro-bats are randomly generated at $\mathrm{N}$ dimension. Here, the bus voltage and line losses are the input micro-bats.

Step 2: Evaluate the objective function for the random number of the micro-bats.

Step 3: The solutions are separated into two groups, the first groups have the minimum best solutions and another group has maximum best solutions.

Step 4: Find the best solution according to the objective function and store the current population.

Step 5: Randomly update the current micro-bats population to update position vector and velocity vector of the micro-bats.

Step 6: Evaluate the objective for the new micro-bats population and select the best solution among the solution.

Step 7: Find the power loss, voltage, real and reactive power flow of the best solution.

Step 8: Check the termination criterion. If it is satisfied terminate or else go to step 9 .

Step 9: Generate the new agents to generate new solutions. Go to Step 2.

Once this process is finished, the system is ready to give the optimum location to place the UPFC.

\section{RESULTS AND DISCUSSION}

The proposed hybrid method is implemented in MATLAB/Simulink 7.10.0 (R2012a) platform, 4GB RAM and Intel(R) core(TM) i5. Here the IEEE 30 bus system is used to validate the proposed method. The numerical results of the proposed method are presented and discussed in this section. The effectiveness of the proposed method is analyzed by comparing with $\mathrm{ABC}$ 
algorithm. Results are discussed in the following Section 4.1.

\subsection{Testing of IEEE 30 bus system}

In the section, the performance analysis of proposed method when applied to IEEE 30 bus system is discussed. Figure 2 gives the layout of the IEEE 30 bus system. It consists of 6 generator buses, 21 load buses and 42 transmission lines. Initially, normal load flow in the IEEE 30 bus system is analyzed using N-R load flow analysis. Consequently, generator outages such as single generator outage and double generator outage are arbitrarily introduced in the generator buses, 1, 2, 6, 13, 22 and 27. Such generator outages cause disturbance in power flow and which further causes increase in power loss the system. Table 1 gives the details of power flow under normal condition, single generator outage condition and after connecting UPFC at optimum location given by bat algorithm. The power loss comparison at different conditions is given in Table 2. It shows the dominating performance of the proposed method. The proposed method effectively reduces the power loss under single generator outage condition.

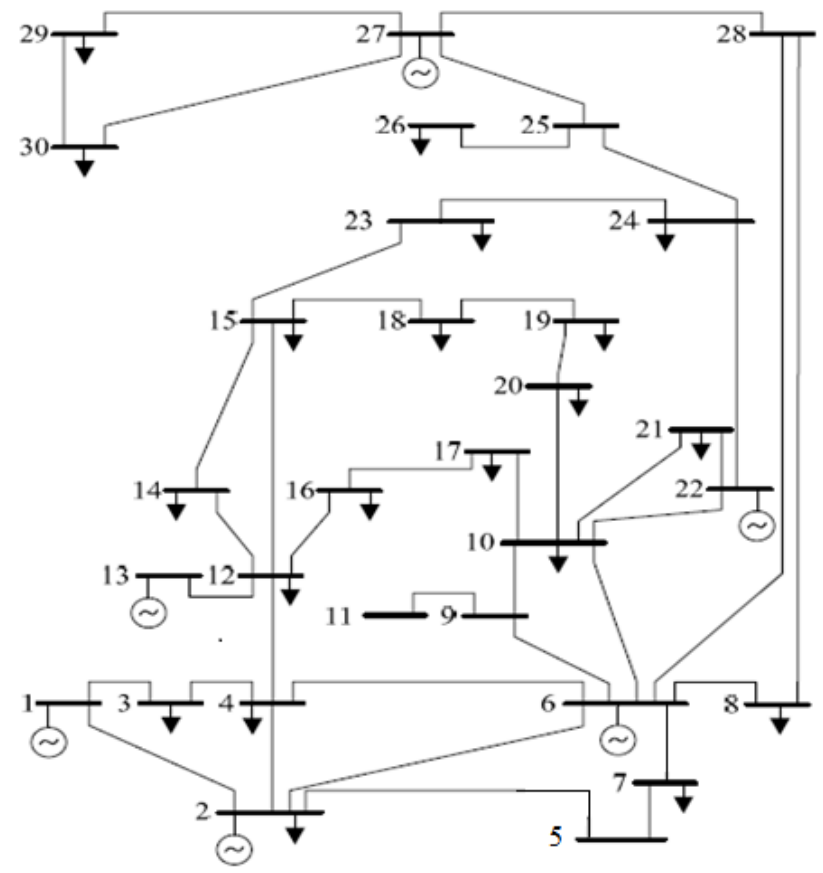

Figure.2: IEEE 30 bus system structure

Table.1: Power flow analysis at single generator outage using the proposed method

\begin{tabular}{|c|c|c|c|c|c|c|c|c|}
\hline \multirow{3}{*}{$\begin{array}{c}\text { Generator } \\
\text { bus no. }\end{array}$} & \multirow{2}{*}{\multicolumn{2}{|c|}{ Best location }} & \multicolumn{6}{|c|}{ Power flow } \\
\hline & & & \multicolumn{2}{|c|}{ Normal } & \multicolumn{2}{|c|}{ Generator outage } & \multicolumn{2}{|c|}{$\begin{array}{l}\text { After connecting UPFC } \\
\text { at optimum location } \\
\text { given by bat algorithm }\end{array}$} \\
\hline & $\begin{array}{c}\text { From } \\
\text { bus }\end{array}$ & $\begin{array}{c}\text { To } \\
\text { bus }\end{array}$ & $\begin{array}{c}\mathrm{P} \\
(\mathrm{MW})\end{array}$ & $\begin{array}{c}\mathrm{Q} \\
(\mathrm{MVAR})\end{array}$ & $\begin{array}{c}\mathrm{P} \\
(\mathrm{MW})\end{array}$ & $\begin{array}{c}\mathrm{Q} \\
(\mathrm{MVAR})\end{array}$ & $\begin{array}{c}\mathrm{P} \\
(\mathrm{MW})\end{array}$ & $\begin{array}{c}\mathrm{Q} \\
(\mathrm{MVAR})\end{array}$ \\
\hline 2 & 2 & 4 & 27.410 & 3.121 & 26.387 & 3.708 & 27.699 & 4.220 \\
\hline
\end{tabular}




\begin{tabular}{|c|c|c|c|c|c|c|c|c|}
\hline 6 & 8 & 28 & 2.971 & 1.398 & 1.963 & 1.3691 & 5.104 & 0.839 \\
\hline 13 & 12 & 16 & 9.529 & 4.077 & 5.564 & 4.766 & 10.835 & 9.409 \\
\hline 22 & 24 & 25 & 1.453 & 3.584 & 1.380 & 1.404 & 3.186 & 6.9701 \\
\hline 27 & 10 & 22 & 4.046 & 6.617 & 0.6402 & 4.803 & 4.359 & 8.549 \\
\hline
\end{tabular}

From the table it is observed that normal power loss of the IEEE 30 bus system is $10.809 \mathrm{MW}$. It may rise to 13.211 MW, when there is a single generator outage problem. The increased power loss can be reduced to
6.445 MW by connecting UPFC at optimum location given by proposed algorithm. This shows the effectiveness of the proposed method.

Table.2: Power loss at single generator outage using the proposed method

\begin{tabular}{|c|c|c|c|c|c|}
\hline \multirow{2}{*}{$\begin{array}{c}\text { Generator } \\
\text { bus no. }\end{array}$} & \multicolumn{2}{|c|}{ Best location } & \multicolumn{3}{c|}{ Power loss in MW } \\
\cline { 2 - 3 } & $\begin{array}{c}\text { From } \\
\text { bus }\end{array}$ & $\begin{array}{c}\text { To } \\
\text { bus }\end{array}$ & \multirow{3}{*}{ Normal } & $\begin{array}{c}\text { Generator } \\
\text { outage }\end{array}$ & $\begin{array}{c}\text { After connecting UPFC at } \\
\text { optimum location given by bat } \\
\text { algorithm }\end{array}$ \\
\hline 2 & 2 & 4 & & & 6.445 \\
\hline 6 & 8 & 28 & \multirow{2}{*}{10.809} & 13.912 & 6.434 \\
\hline 13 & 12 & 16 & 13.724 & 6.460 \\
\hline 22 & 24 & 25 & & 12.795 & 6.400 \\
\hline 27 & 10 & 22 & & 13.119 & 6.445 \\
\hline
\end{tabular}

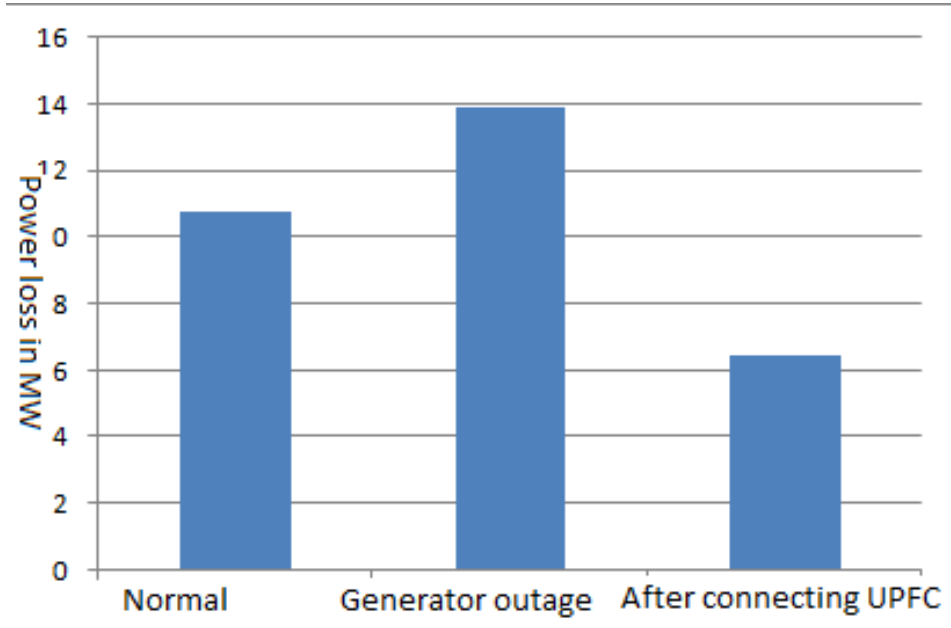

Fig.3 Power loss comparison at single generator outage condition

Subsequently, double generator outage is introduced in the IEEE 30 bus system. At this instant, the power flow of the system is affected. Table 3 gives the details of power flow under normal condition, double generator outage condition and after connecting UPFC at optimum location given by Bat algorithm. Similarly Table 4 gives the power loss comparison under normal condition, double generator outage condition and after connecting UPFC at optimum location given by Bat algorithm. From the table it is observed that normal 
power loss of the IEEE 30 bus system is $10.809 \mathrm{MW}$. It may rise to $16.107 \mathrm{MW}$, when there is a double generator outage problem. The increased power loss can be reduced by connecting UPFC at optimum location given by proposed algorithm. This shows the effectiveness of the proposed method. Figure 3 and Figure 4 shows the power loss comparison at different conditions.

Table.3: Power flow analysis at double generator problem using the proposed method

\begin{tabular}{|c|c|c|c|c|c|c|c|c|}
\hline \multirow{3}{*}{$\begin{array}{c}\text { Generator } \\
\text { bus no. }\end{array}$} & \multicolumn{2}{|c|}{ Best location } & \multicolumn{6}{|c|}{ Power flow } \\
\hline & \multirow{2}{*}{$\begin{array}{c}\text { From } \\
\text { bus }\end{array}$} & \multirow{2}{*}{$\begin{array}{l}\text { To } \\
\text { bus }\end{array}$} & \multicolumn{2}{|c|}{ Normal } & \multicolumn{2}{|c|}{ Generator outage } & \multicolumn{2}{|c|}{ Proposed method } \\
\hline & & & $\begin{array}{c}\mathrm{P} \\
(\mathrm{MW})\end{array}$ & $\begin{array}{c}\mathrm{Q} \\
\text { (MVAR) }\end{array}$ & $\begin{array}{c}\mathrm{P} \\
(\mathrm{MW})\end{array}$ & $\begin{array}{c}\mathrm{Q} \\
\text { (MVAR) }\end{array}$ & $\begin{array}{c}\mathrm{P} \\
(\mathrm{MW})\end{array}$ & $\begin{array}{c}\mathrm{Q} \\
(\mathrm{MVAR})\end{array}$ \\
\hline 2 and 6 & 6 & 7 & 47.479 & 2.110 & 44.327 & 1.292 & 46.898 & 3.715 \\
\hline 2 and 13 & 12 & 15 & 19.674 & 7.796 & 14.813 & 8.708 & 24.454 & 7.528 \\
\hline 6 and 13 & 12 & 15 & 19.674 & 7.796 & 16.202 & 8.216 & 20.936 & 3.666 \\
\hline 22 and 27 & 10 & 20 & 7.665 & 3.278 & 6.801 & 3.866 & 8.722 & 3.762 \\
\hline 13 and 27 & 5 & 7 & 23.744 & 13.824 & 17.948 & 11.419 & 26.427 & 20.810 \\
\hline
\end{tabular}

Table.4: Power loss at double generator problem using the proposed method

\begin{tabular}{|c|c|c|c|c|c|}
\hline \multirow{2}{*}{$\begin{array}{c}\text { Generator } \\
\text { bus no. }\end{array}$} & \multicolumn{2}{|c|}{ Best location } & \multicolumn{3}{|c|}{ Power loss in MW } \\
\hline & $\begin{array}{c}\text { From } \\
\text { bus }\end{array}$ & $\begin{array}{c}\text { To } \\
\text { bus }\end{array}$ & Normal & $\begin{array}{c}\text { Generator } \\
\text { outage }\end{array}$ & $\begin{array}{c}\text { Proposed } \\
\text { method }\end{array}$ \\
\hline 2 and 6 & 6 & 7 & \multirow{5}{*}{10.809} & 16.015 & 6.4546 \\
\hline 2 and 13 & 12 & 15 & & 15.017 & 6.4319 \\
\hline 6 and 13 & 12 & 15 & & 16.107 & 6.4691 \\
\hline 22 and 27 & 10 & 20 & & 14.367 & 6.7079 \\
\hline 13 and 27 & 5 & 7 & & 15.264 & 6.4311 \\
\hline
\end{tabular}

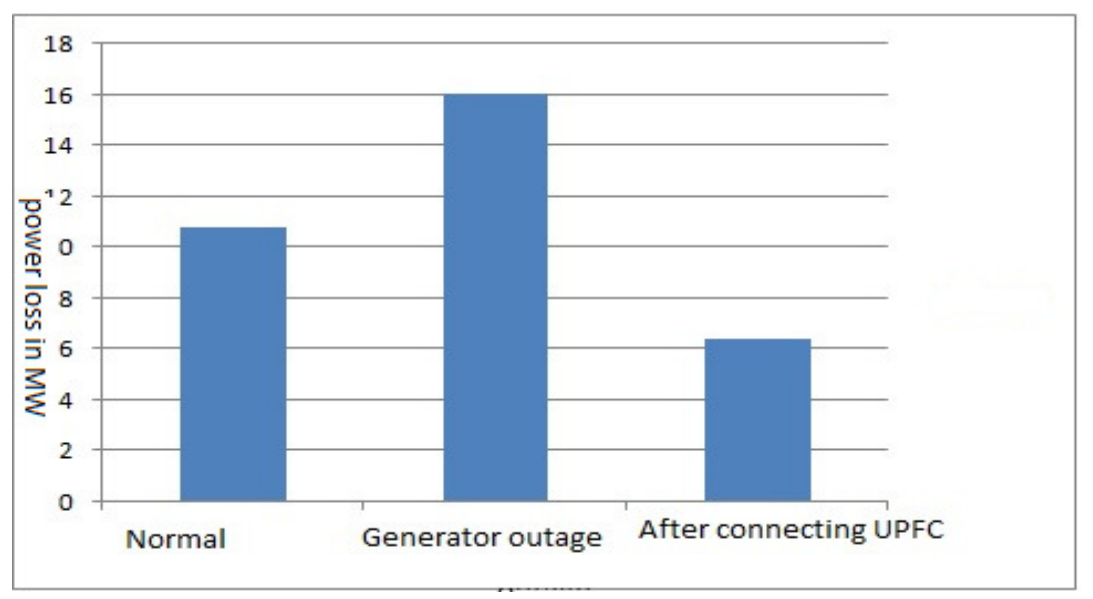




\section{International Journal of Research in Advent Technology, Vol.7, No.5, May 2019 E-ISSN: 2321-9637 Available online at www.ijrat.org}

Fig.4 Power loss comparison at double generator outage condition

\section{CONCLUSION}

This paper describes about minimization of power loss by optimal location of UPFC given by the bat algorithm. By connecting UPFC at the optimum location, and the power flow has been analyzed. The advantage of the proposed method is capability and robustness to solve the complex optimization problem. In the results, system power flows, power loss was analyzed. The comparison of results proved that the proposed method is the most effective technique to reduce power loss of the power system, which is competent over the other techniques.

\section{REFERENCE}

[1] P. Ramasubramanian, G. Uma Prasana, and K. Sumathi, "Optimal Location of FACTS Devices by Evolutionary Programming Based OPF in Deregulated Power Systems", British Journal of Mathematics \& Computer Science, Vol.2, No.1, pp.21-30, 2012

[2] Rakhmad Syafutra Lubis, Sasongko Pramono Hadi, and Tumiran, "Selection of Suitable Location of the FACTS Devices for Optimal Power Flow", International Journal of Electrical \& Computer Sciences, Vol.12, No.3, pp.38-49, 2012

[3] S.Durairaj, and B.Fox, "Optimal Placement of Facts Devices", International Conference on Energy \& Environment, 2008

[4] D. Devaraj, and J. Preetha Roselyn, "Genetic algorithm based reactive power dispatch for voltage stability improvement", International Journal of Electrical Power \& Energy Systems, Vol.32, No.10, pp.1151-1156, December 2010

[5] Chaohua Dai, Weirong Chen, Yunfang Zhu, and Xuexia Zhang, "Reactive power dispatch considering voltage stability with seeker optimization algorithm", Electric Power Systems Research, Vol.79, No.10, pp.1462-1471, October 2009

[6] Rahul J. Shimpi, Rajendra P. Desale, Kunal S. Patil, Jaswantsing L. Rajput and Shailesh B. Chavan, "Flexible AC Transmission Systems", International Journal of Computer Applications, Vol.1, No.15, pp.54-57, 2010

[7] P. K. Dash, S. R. Samantaray, and Ganapati Panda, "Fault Classification and Section Identification of an Advanced Series-Compensated Transmission Line Using Support Vector Machine", IEEE Transaction on Power Delivery, Vol.22, No.1, pp.67-73, January 2007
[8] H O Bansal, H P Agrawal, S Tiwana, A R Singal and L Shrivastava, "Optimal Location of FACT Devices to Control Reactive Power", International Journal of Engineering Science and Technology, Vol.2, No.6, pp.1556-1560, 2010

[9] Xuan Wei, Joe H. Chow, Behruz Fardanesh and Abdel-Aty Edris, "A Common Modeling Framework of Voltage-Sourced Converters for Load Flow, Sensitivity, and Dispatch Analysis", IEEE Transactions On Power Systems, Vol.19, No.2, pp.934-941, May 2004

[10] S. V. Ravi Kumar, and S. Siva Nagaraju, "Functionality of UPFC in Stability Improvement", International Journal of Electrical and Power Engineering, Vol.1, No.3, pp.339-348, 2007

[11] Gerbex, S., Cherkaoui, R., and Germond, A.J., "Optimal location of FACTS devices to enhance power system security", IEEE Bologna Power Tech Conference Proceedings, 2003

[12] Mori, H., and Goto, Y., "A parallel tabu search based method for determining optimal allocation of FACTS in power systems", International Conference on Power System Technology, 2000

[13] Husam I. Shaheen, Ghamgeen I. Rashed, and S.J. Cheng, "Optimal location and parameter setting of UPFC for enhancing power system security based on Differential Evolution algorithm", Electrical Power and Energy Systems, Vol.33, pp.94-105, 2011

[14] Seyed Abbas Taher, and Muhammad Karim Amooshahi, "New approach for optimal UPFC placement using hybrid immune algorithm in electric power systems", Electrical Power and Energy Systems, Vol.43, pp.899-909, 2012

[15] A.R. Phadke, and Manoj Fozdar, K.R. Niazi, "A new multi-objective fuzzy-GA formulation for optimal placement and sizing of shunt FACTS controller", International Journal of Electrical Power \& Energy Systems, Vol.40, No.1, pp.46-53, September 2012

[16]Chuan Wang, Yancheng Liu, Youtao Zhao and Yang Chen, "A hybrid topology scale-free Gaussian-dynamic particle swarm optimization algorithm applied to real power loss minimization", Engineering Applications of Artificial Intelligence, Vol.32, pp.63-75, June 2014.

[17] B.Vijay kumar, "Power System loss minimization by using UPFC placed at optimal location given by Artificial Bee Colony Algorithm" International journal of research in advent technology,vol7, issue 5,2019 . 
[18] Abdelaziz Laifa and Mohamed Boudour, "Optimal Placement and Parameter Settings of Unified Power Flow Controller Device using a Perturbed Particle Swarm Optimization", IEEE International Energy Conference and Exhibition, pp.205-210, 2010

[19] A. Rajabi-Ghahnavieh, M. Fotuhi-Firuzabad, M. Shahidehpour and R. Feuillet, "UPFC for Enhancing Power System Reliability", IEEE Transactions on Power Delivery, Vol.25, No.4, pp.2881-2890, October 2010.

[20] Xin-She Yang, "Bat Algorithm for Multi objective Optimization", pp.1-12, mar 2012.

\section{Author's Biography}

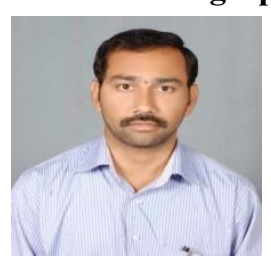

Dr. B. Vijay Kumar was born in Warangal, India, in April 1978. He received the $B$. Tech degree in Electrical \& Electronics Engineering, M. Tech degree in Power Systems Engineering and $\mathrm{Ph} . \mathrm{D}$ in Electrical Engineering from National Institute of Technology, Warangal, India, in 2002, 2008 and 2015 respectively. He is currently working as Asst. professor in EEED of Kakatiya institute of Technology \& Science, Warangal, India. He published 15 research papers in various journal including SCI indexed journals. He also authored three books on power system. His Current research interest includes Enhancement of Power System Stability using FACTS devices and AI techniques. 